\title{
Sex-Based Variation of Gene Expression in the Gonads and Fins of Russian Sturgeon (Acipenser gueldenstaedtii)
}

\author{
Gad Degani1,2*, Akram Hajouj ${ }^{1,2}$, Avshalom Hurvitz ${ }^{3}$ \\ ${ }^{1}$ MIGAL-Galilee Research Institute, Kiryat Shmona, Israel \\ ${ }^{2}$ Tel-Hai Academic College, Upper Galilee, Israel \\ ${ }^{3}$ Israel Kibbutz Dan Fishery, Kibbutz Dan, Israel \\ Email: *gad@migal.org.il
}

How to cite this paper: Degani, G., Hajouj, A. and Hurvitz, A. (2021) Sex-Based Variation of Gene Expression in the Gonads and Fins of Russian Sturgeon (Acipenser gueldenstaedtii). Open Journal of Animal Sciences, 11, 1-10.

https://doi.org/10.4236/ojas.2021.111001

Received: December 16, 2020

Accepted: January 24, 2021

Published: January 27, 2021

Copyright ( 2021 by author(s) and Scientific Research Publishing Inc. This work is licensed under the Creative Commons Attribution International License (CC BY 4.0).

http://creativecommons.org/licenses/by/4.0/

\begin{abstract}
Russian sturgeon (Acipenser gueldenstaedtii) is a primitive freshwater fish and a source of black caviar. The genes involved in sexual determination and differentiation are still unknown and there are no molecular markers for sex identification in this species. Studying the variation of the sex-based differences in genomic sequences and in gene expression in the sturgeon may lead to markers of sex in early stages of development and advances in aquaculture, as well as provide novel insights about the evolution of reproduction, sex determination, and sexual differentiation mechanisms in vertebrates. Previous studies by our and other groups have identified differentially expressed genes in the gonads of adult female and male sturgeon. The current study aimed to test whether these genes were also differentially expressed in non-gonadal tissue, namely fins. We measured by qRT-PCR the mRNA levels of 29 known and novel sex-related genes in the gonads and fins of males (4 years old) and females (7 years old; sexual maturation is earlier in males than in females). Six genes (ATP6, IGFRM, LIA1A, S1A, NPL1A, GAPDH and SOX9) showed higher expression in female fins. However, only ATP6 mRNA levels differed in fins of males and females of the same age (4 years old). These findings underscore the impracticality of sex identification based on gene expression in non-gonadal tissue and the need for genetic sex markers in the Russian sturgeon.
\end{abstract}

\section{Keywords}

Acipenser, Gene Expression, Sexual Maturation, Gonads, Sex Markers

\section{Introduction}

The dramatic increase in the economic value of caviar (eggs in the vitellogenesis 
stage), as well as over-fishing, pollution and habitat destruction of fish species belonging to the Acipenseridae (common name sturgeon) primitive freshwater fish family [1] have encouraged studies of many aspects of biology, genetics, reproduction, growth and adaption to aquaculture conditions of sturgeon species [2]-[8]. The Acipenseridae family includes 25 species, among them Russian sturgeon (Acipenser gueldenstaedtii), which is an important source of black caviar. The native habitats of Russian sturgeon include the Black Sea, the Azov Sea and the Caspian Sea [3].

Among the various aspects of the adaptation of Russian sturgeon growth to aquaculture conditions and in producing caviar, of special note are the hormones that control oogenesis [2] [3] [6], growth [4] [7] and sex-related gonadal development, sex identification and differences in gene expression [8] [9] [10] [11] [12], and these have been studied extensively. Thus, expression differences of various genes among sexes in Russian sturgeon have been described [8] [11] [13]. In those studies, some genes were shown to have higher expression in males, e.g., SOX9, and others in females, e.g., FOX12.

Sex determination and sexual differentiation have been examined on the molecular level due to the fact that no chromosome variation is found between sexes in Acipenseriformes. Based on the observation of sturgeon sex variation, sex determination in the sturgeon is assumed to follow the heterogametic genetic $\mathrm{ZZ/ZW}$ model, where the ZZ genotype leads to the development of males, and the ZW genotype leads to the development of females [9]. In Russian sturgeon, we previously described differential gene expression in gonads [8] [12] [13]. Several genes were more highly expressed in the ovary, e.g., FOX12 and CYP19A1, and DMRT1 was more highly expressed in the male gonad [8] [12].

If similar differences in gene expression could be identified in non-gonadal tissues that, unlike gonads, can be conveniently sampled for analysis without severely wounding the fish, these could be the basis for a sex marker in sturgeon aquaculture. However, to our knowledge, no prior studies have measured gene expression in non-gonadal tissue which was easy to obtain without severely wounding the fish, e.g. fins, and compared it to gonads.

In the present study, we examined the mRNA levels of a panel of candidate genes in the fins of mature male and female Russian sturgeons using quantitative RT-PCR, and compared their expression in fins to that in ovaries and testes.

\section{Materials and Methods}

\subsection{Fish and Sampling Procedure}

Samples were taken from 4- to 7-year-old male and female Russian sturgeon (4 $6 \mathrm{~kg}$ ) from a fish farm on Kibbutz Dan in Israel. They were anaesthetized with $0.03 \%$ tricaine methane sulfonate (MS222, Sigma-Aldrich), and their fork length and body weight were quantified [8]. Gonad samples were removed by endos-copy from males and females as described in detail by [3] and frozen in $1.5-\mathrm{ml}$ tubes with RNALater (Ambion) at $-25^{\circ} \mathrm{C}$ until further analysis. The 
morphology of the ovary and testis was examined by endoscopy as previously described [3]. The fin samples were taken from 11 female (7 years old and 4 years old) and 8 male (4 years old) Russian sturgeons and frozen in 1.5-ml tubes with RNALater at $-25^{\circ} \mathrm{C}$ until further analysis.

\subsection{RNA Extraction}

Tissue samples were removed from RNALater and homogenized using a TissueRuptor (Qiagen). Total RNA was extracted from each sample with TRI Reagent (Sigma) using the manufacturer's protocol. The concentration and integrity of RNA were examined using a Thermo-Fisher Scientific NanoDrop 8000 Spectrophotometer and an Agilent 2100 Bioanalyzer. All RNA samples had $\mathrm{OD}_{260 / 280}$ $\geq 1.8$ and RNA integrity number (RIN) $\geq 7$.

\subsection{Quantitative RT-PCR}

RT, primer design and quantitative PCR using SYBR Green chemistry and DNA primers were performed as previously described [8]. Primer sequences are presented in Appendix A (Table A1). All primers were tested for efficiency (by serial dilutions) and specificity (by melting peak analysis). RT was performed on an Applied Biosystems ABI-9600 with reagents from New England Biolabs. qPCR was performed in technical quadruplicates on an Applied Biosystems ABI-7900HT Sequence Detection System equipped with a 384-well block. Data were analyzed using SDS 2.3 software (Applied Biosystems) and Microsoft Excel. Relative quantification and the $\Delta \mathrm{Cq}$ method were used. Results were normalized to the transcript abundance median of all measured genes per sample (global normalization).

\subsection{Statistics}

The significance of differential mRNA levels as measured by qRT-PCR was estimated by Student's t-test. Differences were considered statistically significant at $P<0.05$.

\section{Results}

We measured by qRT-PCR the mRNA levels of 31 genes, most of them known and some novel sex-related genes in the gonads and fins of males (4 years old) and fe-males ( 4 and 7 years old). The older females were chosen a-priori since Russian sturgeon males reach sexual maturity at an earlier age than females [3]. The genes included hormones, factors, receptors, transcription factors, subunits and nucleosome protein genes, and were selected based on differential expression between the sexes in gonads, as observed by our and other groups' prior studies (sources are listed in Table A1).

Of these, 22 genes could be reliably quantified in gonads. Among these, transcripts of GPR4, EOMES, PO5F1, ZP2 and ZP4 had significantly higher levels in the ovary, while LH and GH mRNA levels were higher in the testis (Figure 1 and Table 1). 
Table 1. Genes showing significantly differential expression in the fins and gonads of 4-year-old males and 7-year-old females Russian sturgeon.

\begin{tabular}{lcl}
\hline Tissue & Gene & \\
\hline LH & Significantly higher in males \\
\cline { 2 - 3 } Gonads & GPR4 & \\
& EOMES & Significantly higher in females \\
POF1 & \\
ZP2 & \\
ZP4 & \\
SOX9 & \\
ATP6 & \\
Fins & IGF1R & \\
& LIS1A & \\
& NPL1A & \\
GAPDH & \\
\hline
\end{tabular}

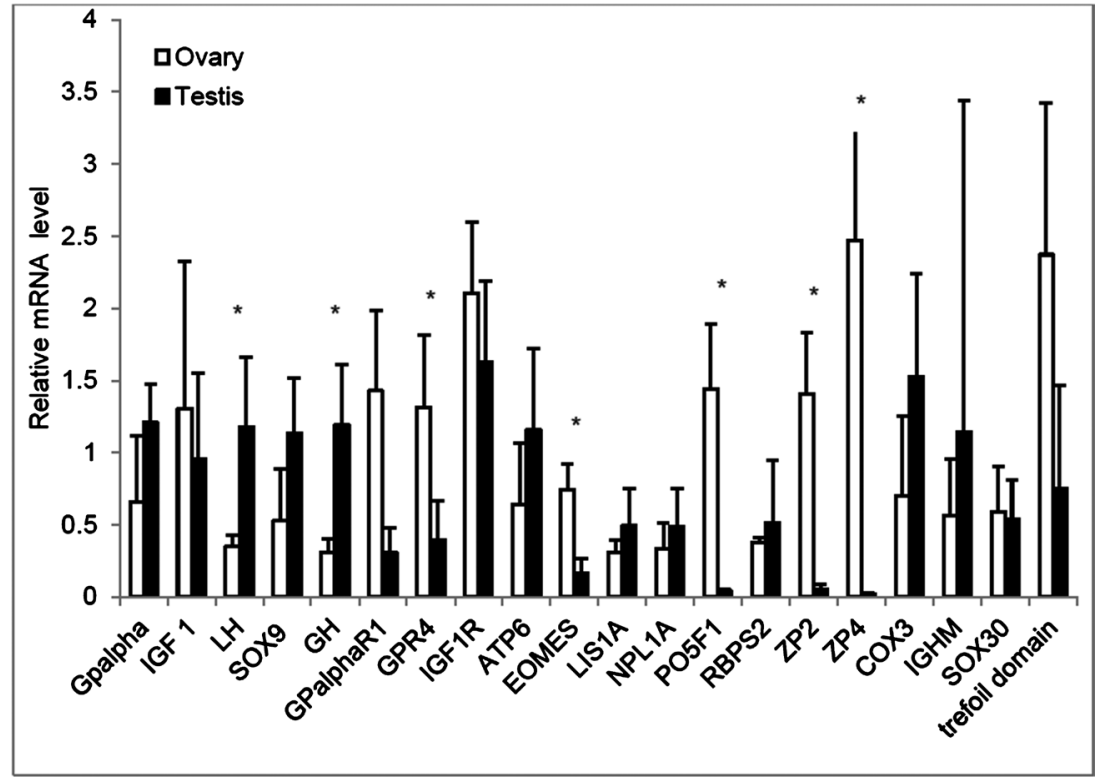

Figure 1. Relative mean mRNA levels (based on qRT-PCR) of the listed genes in gonadal samples from five female 7 -years old and four male 4 -year-old sturgeons. ${ }^{*}: P<0.05$ (t-test). Mean + standard error (SE).

The differences between ovary and testis mRNA levels of Gpalpha1, IGF1, IGFR1, SOX9, ATP6, LIS1A, NPL1A, RBPS2, COX3, IGHM, SOX30 and trefoil domain protein were not statistically significant.

In the fins of 4-year-old males and 7-year-old females, 22 of the 32 genes could be reliably quantified by qRT-PCR. Of these, six genes (ATP6, IGFRM, LIS1A, GAPDH, NPL1A and SOX9) showed significantly higher mRNA levels in 
females compared to males (Figure 2 and Table 1). However, when the male fin samples were compared to the fins of similarly aged females (4 years old), the only significant expression difference observed was in the ATP6 gene, which showed $\sim 5 \mathrm{X}$ higher expression in the female samples (Figure 3 ).

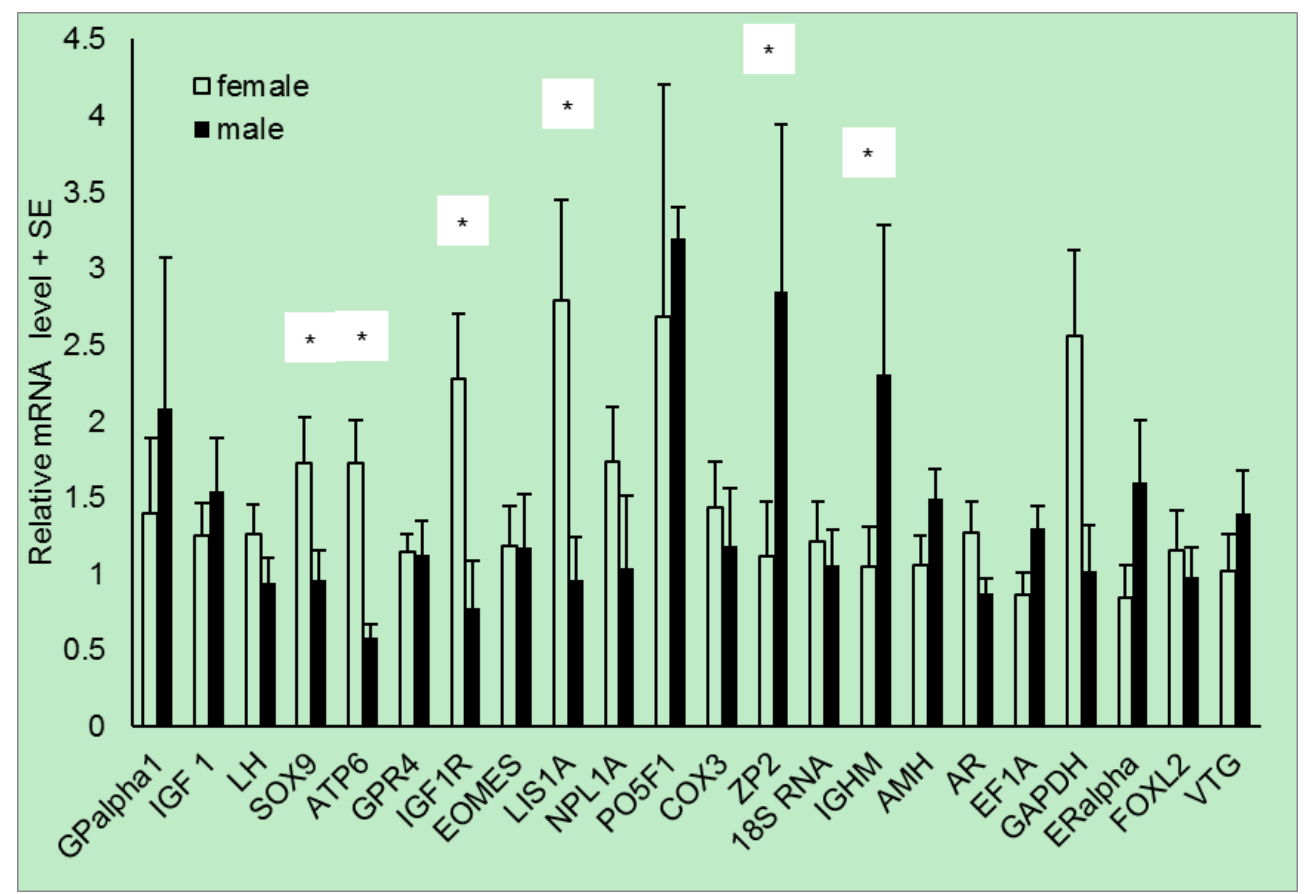

Figure 2. Relative mean mRNA levels (based on qRT-PCR) of the listed genes in fin samples from 11 female (7 years old) and 8 male (4 years old) Russian sturgeons. ${ }^{*}: P<0.05$ (t-test). Mean + standard error (SE).

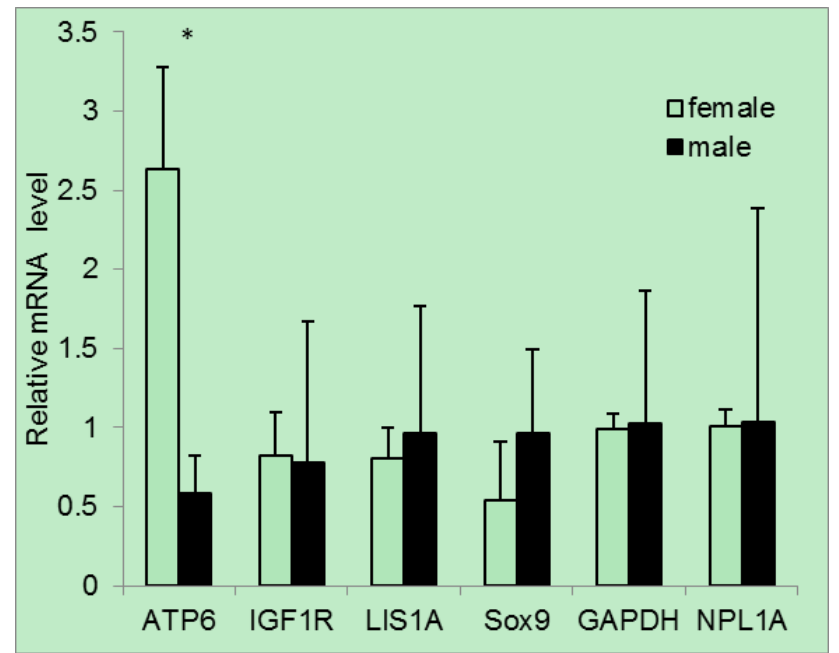

Figure 3. Relative mean mRNA levels (based on qRT-PCR) of the listed genes in fin samples from 10 female (4 years old) and 8 male (4 years old) Russian sturgeons. ${ }^{*}$ : $\mathrm{P}<0.05$; (t-test), Mean + standard error (SE).

\section{Discussion}

The gametogenesis process during growth and/or maturation of fish, as in 
other vertebrates, is mainly controlled by the endocrine system according to the BPG-_axis. Most of the genes involved in oogenesis [5] [6] [8] and spermatogenesis [14] [15] code for sex hormones and endocrine receptors that control the differentiation. The genes involved in paracrine and autocrine secretion have been less studied [16] [17] than those involved hormone control of reproduction.

In the present study, several genes in Russian sturgeon had significant differences in expression between ovary and testis, in agreement with prior studies [8] [12]. Thus, sex-based differences in the gonadal transcriptomes of various sturgeon species were studied [8] [11] [13] [18] [19]. These studies identified genes which showed higher expression in male gonads, e.g. SOX9, and others in females, e.g. FOX12. Our previous study found higher expression in the ovary for the genes ZP1, Cyp19p450, RBPS2 and Fox12 [8] in the testis. In the present study, the mRNA levels of EOMES, PO5F1, ZP2 and ZP4 were found to be significantly higher in the ovary, while the mRNA levels of $\mathrm{LH}$ and GH were higher in the testis.

Different endocrine and autocrine/paracrine functions of the same hormone are not well understood, but have been described in other fish species. For example, in blue gourami, the mRNA levels of GnRH1 and GnRH3 were higher in oocytes at the previtellogenic stage compared to the vitellogenic and follicular oocyte maturation (FOM) stages [17]. The different transcription levels of GnRH1 and GnRH3 in the brain and of FSH and LH in the pituitary compared to mRNA levels changed in the ovary during oogenesis, supporting the hypothesis that differences exist between the endocrine and autocrine/paracrine functions of these hormones [17].

Sexual maturation of Russian sturgeon occurs earlier in males than in females. In this study, we observed higher expression of ATP6, IGFRM, LISA1A, GAPDH, SOX9 and NPL1A in the fins of 7-year-old females, compared to 4-year-old males. However, only ATP6 mRNA levels diverged between the fins of similarly aged (4-year-old) males and females. While the difference in ATP6 mRNA levels suggests a sex-based difference in metabolic and oxidative processes soon after sexual differentiation, this finding must be validated in a larger sample. Overall these results do not support the notion that gene expression differs substantially between the sexes in non-gonadal tissues of Russian sturgeon.

Thus, identifying DNA sequence-based genetic markers for sex in this species, which could be reliably detected in easily accessible non-gonadal tissues, remains the most promising direction for future research and development. Efforts are underway to identify such markers.

\section{Author Contributions}

Conceptualization, Gad Degani; Formal analysis, Akram Hajouj; Investigation, Gad Degani, Akram Hajouj; Resources, Avshalom Hurvitz; Supervision, Gad Degani, Avshalom Hurvitz; Visualization, Akram Hajouj; Writing-original draft, Gad Degani. 


\section{Funding}

This study was funded by an internal grant from MIGAL.

\section{Acknowledgements}

The authors would like to thank Ari Meerson (MIGAL) for many helpful suggestions and technical assistance, and Hila Yehuda (MIGAL) for technical assistance.

\section{Conflicts of Interest}

The authors declare no conflicts of interest regarding the publication of this paper.

\section{References}

[1] Birstein, V.J., Bemis, W.E. and Waldman, J.R. (1997) The Threatened Status of Acipenseriform Species: A Summary. Environmental Biology of Fishes, 48, 427-435. https://doi.org/10.1023/A:1007382724251

[2] Hurvitz, A., Degani, G., Goldberg, D., Din, S.Y., Jackson, K. and Levavi-Sivan, B. (2005) Cloning of FSH $\beta, \mathrm{LH} \beta$, and Glycoprotein a Subunits from the Russian Sturgeon (Acipenser gueldenstaedtii), $\beta$-Subunit mRNA Expression, Gonad Development, and Steroid Levels in Immature Fish. General and Comparative Endocrinology, 140, 61-73. https://doi.org/10.1016/j.ygcen.2004.09.019

[3] Hurvitz, A., Jackson, K., Degani, G. and Levavi-Sivan, B. (2007) Use of Endoscopy for Gender and Ovarian Stage Determinations in Russian Sturgeon (Acipenser gueldenstaedtii) Grown in Aquaculture. Aquaculture, 270, 158-166. https://doi.org/10.1016/j.aquaculture.2007.05.020

[4] Yom Din, S., Hurvitz, A., Goldberg, D., Jackson, K., Levavi-Sivan, B. and Degani, G. (2008) Cloning of Russian Sturgeon (Acipenser gueldenstaedtii) Growth Hormone and Insulin-Like Growth Factor I and Their Expression in Male and Female Fish during the First Period of Growth. Journal of Endocrinological Investigation, 31, 201-210. https://doi.org/10.1007/BF03345591

[5] Yaron, Z. and Levavi-Sivan, B. (2011) Endocrine Regulation of Fish Reproduction. In: Farrell, A.P., Ed., Encyclopedia of Fish Physiology: From Genome to Environment, Academic Press, San Diego, 1500-1508.

[6] Yom-Din, S., Hollander-Cohen, L., Aizen, J., Boehm, B., Shpilman, M., Golan, M., Hurvitz, A., Degani, G. and Levavi-Sivan, B. (2016) Gonadotropins in the Russian Sturgeon: Their Role in Steroid Secretion and the Effect of Hormonal Treatment on Their Secretion. PLOS ONE, 11, e0162344. https://doi.org/10.1371/journal.pone.0162344

[7] Degani, G., Din, S.Y. and Hurvitz, A. (2017) Transcription of Insulin-Like Growth Factor Receptor in Russian Sturgeon (Acipenser gueldenstaedtii) Ovary during Oogenesis. Universal Journal of Agricultural Research, 5, 119-124. https://doi.org/10.13189/ujar.2017.050206

[8] Degani, G., Hurvitz, A., Eliraz, Y. and Meerson, A. (2019) Sex-Related Gonadal Gene Expression Differences in the Russian Sturgeon (Acipenser gueldenstaedtii) Grown in Stable Aquaculture Conditions. Animal Reproduction Science, 200, 75-85. https://doi.org/10.1016/j.anireprosci.2018.11.013 
[9] Eenennaam, J.P.V. and Doroshov, S.I. (1998) Effects of Age and Body Size on Gonadal Development of Atlantic Sturgeon. Journal of Fish Biology, 53, 624-637. https://doi.org/10.1111/j.1095-8649.1998.tb01006.x

[10] Fontana, F. (1994) Chromosomal Nucleolar Organizer Regions in Four Sturgeon Species as Markers of Karyotype Evolution in Acipenseriformes (Pisces). Genome, 37, 888-892. https://doi.org/10.1139/g94-126

[11] Hagihara, S., Yamashita, R., Yamamoto, S., Ishihara, M., Abe, T., Ijiri, S. and Adachi, S. (2014) Identification of Genes Involved in Gonadal Sex Differentiation and the Dimorphic Expression Pattern in Undifferentiated Gonads of Russian Sturgeon Acipenser gueldenstaedtii Brandt \& Ratzeburg, 1833. Journal of Applied Ichthyology, 30, 1557-1564. https://doi.org/10.1111/jai.12588

[12] Chen, J., Wang, W., Tian, Z.H., Dong, Y., Dong, T., Zhu, H., Zhu, Z.Y., Hu, H.X. and $\mathrm{Hu}, \mathrm{W}$. (2018) Efficient Gene Transfer and Gene Editing in Sterlet (Acipenser ruthenus). Frontiers in Genetics, 9, 117. https://doi.org/10.3389/fgene.2018.00117

[13] Chen, Y., Xia, Y., Shao, C., Han, L., Chen, X., Yu, M. and Sha, Z. (2016) Discovery and Identification of Candidate Sex-Related Genes Based on Transcriptome Sequencing of Russian Sturgeon (Acipenser gueldenstaedtii) Gonads. Physiological Genomics, 48, 464-476. https://doi.org/10.1152/physiolgenomics.00113.2015

[14] Degani, G., Jackson, K., Goldberg, D., Sarfati, R. and Avtalion, R.R. (2003) BFSH, $\beta \mathrm{LH}$ and Growth Hormone Gene Expression in Blue Gourami (Trichogaster trichopterus, Pallas 1770) during Spermatogenesis and Male Sexual Behavior. Zoological Science, 20, 737-743. https://doi.org/10.2108/zsj.20.737

[15] Degani, G. (2015) 11-Ketotesterone (KT-11), Estradiol Estradiol (E2) Level and Cytochrome P450 (bgCYP19a) Ttranscription of in the Testis of Male Blue Gourami (Trichogaster trichopterus). International Journal of Scientific Research, 4, 641-643.

[16] Degani, G. (2014) Expression of SOX3 and SOX9 Genes in Gonads of Blue Gourami. Advances in Biological Chemistry, 4, 322-330. http://dx.doi.org/10.4236/abc.2014.45037

[17] Degani, G. (2014) Involvement of GnRH and Gonadotropin Genes in Oocyte Development of Blue Gourami Females (Trichogaster trichopterus). Advances in Biological Chemistry, 4, 197-202. http://dx.doi.org/10.4236/abc.2014.43024

[18] Wang, W., Zhu, H., Dong, Y., Tian, Z.H., Dong, T., Hu, H.X. and Niu, C.J. (2017) Dimorphic Expression of Sex-Related Genes in Different Gonadal Development Stages of Sterlet, Acipenser ruthenus, a Primitive Fish Species. Fish Physiology and Biochemistry, 43, 1557-1569. https://doi.org/10.1007/s10695-017-0392-x

[19] Burcea, A., Popa, G.-O., Florescu (Gune), I.E., Maereanu, M., Dudu, A., Georgescu, S.E. and Costache, M. (2018) Expression Characterization of Six Genes Possibly Involved in Gonad Development for Stellate Sturgeon Individuals (Acipenser stellatus, Pallas 1771). International Journal of Genomics, 2018, Article ID: 7835637. https://doi.org/10.1155/2018/7835637

[20] Pormehr, A.L., Pourkazemi, M., Yarmohammadi, M., Banismaeili, Y. and Sanati, M.H. (2013) Phylogenetic and Sequence Analysis of the Growth Hormone Gene of Two Sturgeons, Huso huso and Acipenser gueldenstaedtii. Progress in Biological Sciences, 3, 99-105.

[21] Fajkowska, M., Głowacka, D.K., Adamek-Urbańska, D., Ostaszewska, T., Krajnik, K.A. and Rzepkowska, M. (2019) Sex-Related Gene Expression Profiles in Various Tissues of Juvenile Russian Sturgeon (Acipenser gueldenstaedtii). Aquaculture, 500, 532-539. https://doi.org/10.1016/j.aquaculture.2018.10.066 


\section{Appendix A}

Table A1. Nucleotide sequences of primers for quantification of gene expression using qRT-PCR.

\begin{tabular}{|c|c|c|c|c|}
\hline Abbr. name & Gene name & Direction & Sequence & Source \\
\hline ATP6 & ATP synthase subunit a & Forward & ACTCGGCCTACTCACCTACA & [8] \\
\hline ATP6 & ATP synthase subunit a & Reverse & ACGGTAGCAAGTCATAGGGG & [8] \\
\hline EOMES & Eomesodermin homolog & Forward & CAAATCCTTGCCCCTCCAGA & [8] \\
\hline EOMES & Eomesodermin homolog & Reverse & CCCATCCTGCTGCCATTGAA & {$[8]$} \\
\hline LIS1A & Lissencephaly-1 homolog A & Forward & AGCTCCTATCCCACCATCCT & [8] \\
\hline LIS1A & Lissencephaly-1 homolog A & Reverse & GCCAACCAGTGTCATAAGGC & [8] \\
\hline NPL1A & Nucleosome assembly protein 1-like 1-A & Forward & CCCACATCGAAGCCAAGTTC & [8] \\
\hline NPL1A & Nucleosome assembly protein 1-like 1-A & Reverse & GGCTGGTAGAGTGCTGCATA & [8] \\
\hline PO5F1 & POU domain, class 5 , transcription factor 1 & Forward & TGGAGAAAGATGTGGTGCGG & [8] \\
\hline PO5F1 & POU domain, class 5 , transcription factor 1 & Reverse & TCGAAATACTGCCCCTCTGC & [8] \\
\hline RBPS2 & RNA-binding protein with multiple splicing 2 & Forward & CCCCATGCTGCCTTCACTTA & {$[8]$} \\
\hline RBPS2 & RNA-binding protein with multiple splicing 2 & Reverse & GGCTAGTGTCAGATGGAGAAGG & [8] \\
\hline $\mathrm{ZP} 2$ & Zona pellucida sperm-binding protein 2 & Forward & GCCCCAACAGCTTCCTAACT & [8] \\
\hline $\mathrm{ZP} 2$ & Zona pellucida sperm-binding protein 2 & Reverse & GTAGCCTTTTGACCGAGCCT & [8] \\
\hline $\mathrm{ZP} 4$ & Zona pellucida sperm-binding protein 4 & Forward & CAGACCAATGGCATCCCСTT & [8] \\
\hline $\mathrm{ZP} 4$ & Zona pellucida sperm-binding protein 4 & Reverse & CGACCTTGCTAAACTGCTGC & [8] \\
\hline $\operatorname{cox} 3$ & Cytochrome $\mathrm{c}$ oxidase subunit 3 & Forward & GGGCACATTTCAAGGACACC & [8] \\
\hline $\operatorname{cox} 3$ & Cytochrome $\mathrm{c}$ oxidase subunit 3 & Reverse & GGGCTAGACTTGCGTGGTAA & [8] \\
\hline IGHM & Ig mu chain $\mathrm{C}$ region & Forward & GCGGGGACAAATTCTTCTGC & [8] \\
\hline IGHM & Ig mu chain $\mathrm{C}$ region & Reverse & TGGCGAGAGAAGAAACACCG & [8] \\
\hline SOX30 & Transcription factor SOX30 & Forward & CTTCCCCACCCACACGTTTA & {$[8]$} \\
\hline SOX30 & Transcription factor SOX30 & Reverse & AGGGAATGGAAAGCGAGGTG & [8] \\
\hline $\mathrm{GPa}$ & Luteinizing hormone alpha subunit & Forward & GACTCCGATTTTCCAGTGTGTG & [2] \\
\hline $\mathrm{GPa}$ & Luteinizing hormone alpha subunit & Reverse & GCCTCTGAAGTAATGTTCTTGGG & [2] \\
\hline IGF1 & Insulin-like growth factor 1 (IGF1) & Forward & TGTGTGGGGAGAGAGGCTT & [6] \\
\hline IGF1 & Insulin-like growth factor 1 (IGF1) & Reverse & TCTGGAAGCAGCACTCGTTC & [6] \\
\hline $\mathrm{LH}$ & Luteinizing hormone & Forward & CCAAAGTGCСТССТСАТССА & [2] \\
\hline $\mathrm{LH}$ & Luteinizing hormone & Reverse & CGTGGAGAGAGCGGATTTGA & [2] \\
\hline $\mathrm{GH}$ & Growth hormone & Forward & GCAACGTCACTCCAGCAAAA & {$[20]$} \\
\hline GH & Growth hormone & Reverse & CTCCACGTCTGATCGCTGTT & {$[20]$} \\
\hline GPR4 & G-protein coupled receptor 4 & Forward & ACCGATTCCTAGCTGTGGTC & {$[8]$} \\
\hline GPR4 & G-protein coupled receptor 4 & Reverse & CAAACCACCACACACACCAG & [8] \\
\hline IGF1R & Insulin-like growth factor Receptor & Forward & GCATCGAGTTCCTGAACGA & [7] \\
\hline IGF1R & Insulin-like growth factor receptor & Reverse & AGCGAGCGTAGGTAGCTCTT & [7] \\
\hline Trefoil domain & Trefoil (P-type) domain & Forward & TGTATGTCCTGACGGTGCTC & [8] \\
\hline
\end{tabular}




\section{Continued}

\begin{tabular}{|c|c|c|c|c|}
\hline Trefoil domain & Trefoil (P-type) domain & Reverse & AGAGCTTAGAGGGGCCACAG & [8] \\
\hline 18S RNA & $18 \mathrm{~S}$ ribosomal RNA gene & Forward & CCATAAACGATGCCGACTGG & [21] \\
\hline 18S RNA & $18 \mathrm{~S}$ ribosomal RNA gene & Reverse & TGAGGTTCCCCGTGTTGAGT & [21] \\
\hline GAPDH & Glyceraldehyde 3-phosphate dehydrogenase & Forward & CTGGCATTGCTCTGAATGAC & [21] \\
\hline GAPDH & Glyceraldehyde 3-phosphate dehydrogenase & Reverse & TCCACGACTCTGTTGCTGTAA & [21] \\
\hline EF1A & Elongation factor 1-alpha (EF1A) & Forward & TTCGCTCCTGTCAACATCAC & [21] \\
\hline EF1A & Elongation factor 1-alpha (EF1A) & Reverse & ACGTTGTCTCCAGGATTTGC & [21] \\
\hline $\mathrm{AMH}$ & Anti-mullerian hormone & Forward & GTCCCCAGAGCGGATTCAAA & [21] \\
\hline $\mathrm{AMH}$ & Anti-mullerian hormone & Reverse & GGTTCCCTTTCTCCGGCATT & [21] \\
\hline AR & Androgen receptor (AR) & Forward & TACAGGTGGCGAGTTCCCTA & [21] \\
\hline $\mathrm{AR}$ & Androgen receptor (AR) & Reverse & GCACCCCATTCGTTGTTCTG & [21] \\
\hline CYP19 & Cytochrome P450 aromatase (CYP19) & Forward & AATGTGTGCTGGAGATGCTG & [21] \\
\hline CYP19 & Cytochrome P450 aromatase (CYP19) & Reverse & CCAGCAGTTTCCTCTCAACC & [21] \\
\hline DMRT1 & Doublesex and mab-3 related transcription factor $1(\mathrm{dmrt} 1)$ & Forward & GAAGGCACTGGAAACAGCTC & [21] \\
\hline DMRT1 & Doublesex and mab-3 related transcription factor $1(\mathrm{dmrt} 1)$ & Reverse & GCAGATTGGTACGGCTCTCT & [21] \\
\hline ERA & ESR1a mrna for estrogen receptor alpha1 & Forward & CAGGCCAAGTATGGAAGGCA & [21] \\
\hline ERA & ESR1a mrna for estrogen receptor alphal & Reverse & CACCGCACAGAACCTCATCT & [21] \\
\hline ERB & Estrogen receptor beta & Forward & TATCTGCCCCGCTACAAACC & [21] \\
\hline ERB & Estrogen receptor beta & Reverse & CGCTCTCTTCTTGTACCGCA & [21] \\
\hline FOXL2 & Forkhead box L2 & Forward & AGGCAGTGTAAGTGACGAGA & [21] \\
\hline FOXL2 & Forkhead box L2 & Reverse & ATCCTAAACAGTCGGGGCAA & [21] \\
\hline SOX9 & Transcription factor SOX-9 & Forward & CAGCAAAACACTCGGGAAA & [21] \\
\hline SOX9 & Transcription factor SOX-9 & Reverse & TGGTACTTGTAATCGGGGTGA & [21] \\
\hline STAR & Steroidogenic acute regulatory protein & Forward & TCGGAAACGAGAAGACAACA & [21] \\
\hline STAR & Steroidogenic acute regulatory protein & Reverse & GACCAGCAAACCTCTTCAGC & [21] \\
\hline VTG & Vitellogenin & Forward & CAAGTCAGCTAACCCAGCCA & [21] \\
\hline VTG & Vitellogenin & Reverse & GCATGTTCAGGATCCСССТC & [21] \\
\hline
\end{tabular}

